УДК 81'255.2

DOI: 10.33184/YVDK-2021-04-30.7

Е.А. Морозкина (проф. БашГУ, г. Уфа),

Т.Р. Алтынгужин (асс. БашГУ, г. Уфа)

\title{
СТРУКТУРНО-СЕМИОТИЧЕСКИЕ ОСОБЕННОСТИ ТЕКСТА В ХУДОЖЕСТВЕННОМ ПЕРЕВОДЕ
}

\begin{abstract}
В статье рассматривается структурно-семиотические особенности художественного текста при переводе англоязычного романа американского писателя Н. Готорна "Marble Faun" (1860) на русский язык. Утверждается, что структура означенного романа обладает сложными внутренними связями, формируемыми при помощи мифологического семиотического пространства, а также семиотических пространств различных видов искусств, среди которых выделяется семиотическое пространство таниа. Доказывается, что недостаточно внимательное отночение переводчика к языковым средствам, использованным для формирования отдельных семиотических пространств, искажает структурные особенности оригинала и приводит $\kappa$ потере важных смысловых оттенков в художественном переводе.
\end{abstract}

Ключевые слова: семиотика, семиотическое пространство, Мраморный Фавн, Натаниэль Готорн, художественный перевод.

The article studies the role of structural and semiotic features of a literary text in the translation of the English-language novel "Marble Faun" (1860) by the American writer N. Hawthorne into Russian. It is stated that the structure of the novel mentioned has complex internal relations formed with the help of mythological semiotic space, as well as semiotic spaces of various types of arts, among which stands out the semiotic space of dance. It is proved that the translator's inattentive attitude to the linguistic means used to form separate semiotic spaces 
distorts the structural cohesion of the original text and leads to the loss of important semantic nuances in the translation text.

Keywords: semiotics, semiotic space, Marble Faun, Nathaniel Hawthorne, literary translation

Художественный текст представляет собой сложную гетерогенную структуру, которая способна условно разворачиваться в плоскостях нескольких семиотических пространств, которые, тем не менее, в совокупности, образуют единый семиотический континуум. Отметим, что под семиотическим пространством в статье понимается «некий семиотический континуум, заполненный разнотипными и находящимися на разном уровне организации семиотическими образованиями» [Лотман 1992: 11-12], будь то знаки, символы, коды, которые в совокупности образуют универсум, необходимый для понимания данных семиотических образований. К сожалению, данная особенность организации художественного текста как отдельного семиотического образования не всегда принимается во внимание в процессе перевода, что, в результате, не только стилистически обедняет текст перевода, но также приводит к утрате имплицитных смыслов, изначально актуализированных автором оригинала при помощи определенных структурных решений. Таким образом, актуальность настоящей статьи определяется необходимостью исследования художественного текста как объекта перевода, с точки зрения внутренних структурно-семиотических связей текста, обусловливающих его смысловое наполнение.

Цель статьи заключается в изучении единого семиотического пространства текста оригинала, которое обладает сложными структурными связями, нашедшими отражение в лингвосистеме исходного текста и требующих для сохранения имплицитных смыслов адекватной передачи в тексте перевода.

Осуществление поставленной цели требует решения таких задач, как:

- выявление языковых средств, использованных автором оригинала для создания определенных структурно-семиотических связей внутри текста; 
- формирование на основе означенных выше языковых единиц лингвосемиотических рядов, актуализирующих те или иные семиотические пространства текста оригинала;

- анализ и интерпретация семиотических пространств текстов оригинала и перевода, содержащих многочисленные смысловые оттенки и определяющих структуру текстов.

Методы исследования, использованные в статье, включают метод наблюдения над языковым материалом, методы анализа и синтеза, метод сопоставительного анализа, метод семантического анализа, метод сплошной выборки.

Материалом исследования послужили англоязычный роман “The Marble Faun” (1860 г.), написанный американским писателем XIX в. Натаниэлем Готорном, и его русскоязычная версия перевода, выполненная неизвестным переводчиком в том же году. В означенном романе пересекаются семиотические пространства условно реального и мифологического миров, сопряжение которых, в частности, осуществляется автором оригинала посредством образа одного из персонажей, отождествляемого в тексте с образом Фавна.

В древнеримской мифологии Фавн известен как доброе, жизнерадостное и плутовское божество, покровитель лесов, полей и пастухов, которые устраивали в его честь празднества, сопровождаемые песнями и танцами. Неотъемлемым атрибутом образа Фавна, часто уподобляемого персонажам древнегреческой мифологии Пану и сатирам, являлись флейта, сиринга или свирель, под музыку которых устраивались веселые и шумные хороводы и пляски. В связи с этим, представители самых разных видов искусств, таких как литература, скульптура, живопись, музыка, декоративно-прикладное или сценическое искусства, изображали и представляли Фавна играющим на флейте или танцующим. Таким образом, можно утверждать, что семиотическое пространство мифа, связанного с образом Фавна, тесно сплетено с семиотическом пространством искусства. Данная связь лингвистически реализуется автором оригинала, который вводит в текст набор определенных языковых средств, актуализирующих, с одной стороны, мифологическое семиотическое пространство, с другой - семиотические пространства тех репрезентирующих образ Фавна видов искусств, аллюзии, реминисценции и отсылки к которым встречаются в 
тексте романа. Так, например, в тексте присутствуют детальное упоминание старинных барельефов и ваз, которые изображали танцующего Фавна, а также воспроизведение танца Фавна с нимфами и музыки, исполняемой на флейте, инструменте, приписываемом образу Фавна. Соответственно, единое семиотическое пространство текста романа, ввиду неоднородности, свойственной, согласно Ю. М. Лотману [Лотман 1992: 16-33], любой семиотической системе, включает в себя, своего рода, семиотические субпространства, связанные с мифологией и различными видами искусства. Данные семиотические субпространства актуализированы в тексте романа при помощи определенных языковых средств в форме, известной как «текст в тексте». Иными словами, каждое семиотическое субпространство образует в структуре текста всего произведения, своего рода, отдельный «текст» с особыми, характерными только для него типами лексем. В совокупности эти «тексты» формируют структуру романа, выстраиваясь, по лотмановскому принципу «текста в тексте» [Лотман: 1992: 148], что активизирует «процесс восприятия основного текста с помощью переключения внимания читателя из одной семиотической системы в другую» [Морозкина, Биктимирова 2018: 239]. Таким образом, анализируемый текст «условно можно рассматривать как некое структурное целое, состоящее по ... формообразующему признаку из отдельных частей» [Морозкина, Морозкин, Сафина 2017: 271].

В настоящей статье предлагается исследование языковой репрезентации семиотического пространства, главным образом, танца, поскольку в анализируемом тексте данное пространство неоднократно оказывается одновременно сопряженным и с мифологическим семиотическим пространством, и с семиотическими пространствами других видов искусства. Последний случай взаимоналожения нескольких семиотическим пространств представляет особый интерес для изучения, поскольку в некоторой степени затрагивает проблему интерсемиотического перевода знаков параллельно нескольких невербальных семиотических систем в знаки естественного языка.

Анализ различных эпизодов текста, содержащих описание танцев, позволил сформировать лингвосемиотический ряд, 
включающий в свой состав глаголы, которые описывают танцевальные движения, такие как «to let her dance (позволить eŭ таниевать), to approach (приближаться), to dance to the cadence (танцевать в такт), to ехтетрогіzе nеw steps (импровизировать новые na), to shake the tambourine (трясти бубном), to lead the throng (вести за собой толпу), tо соте to pause (остановиться), to run in advance (опережать), to approach (приближаться), to fling oneself (бросаться/рваться)》 и др [Алтынгужин 2020: 569]. Следует отметить, что глагольная конструкция с возвратным местоимением, приведенная последней в означенном выше лингвосемиотическом ряду, используется в тексте оригинала для описания движений одновременно двух персонажей, отождествляемых с танцующими Фавном и нимфой. Используя прием лексического повтора, автор оригинала стремится показать единый порыв двух героев, вместе неспособных противостоять желанию танцевать. В одном случае, переводчик передает причастный оборот flinging himself, использованный в оригинале для описания движений героя, уподобляемого Фавну, как принимая noзы, в другом - для передачи глагольной конструкции в прошедшем времени flung herself, описывающей движения героини, сравниваемой с нимфой, переводчик предлагает вариант предалась веселости. Прибегая к приему лексической замены, переводчик снимает в тексте перевода оригинальный прием повтора, в результате чего «восприятие смысловой составляющей ... остается неполным» [Морозкина, Камалов, Кожевников 2014: 1004].

Примечательно, что семиотическое пространство условно реального мира произведения намеренно актуализировано автором оригинала менее ярко по сравнению с семиотическими пространствами мифологического мира, а также различных видов искусств. Пространства мифа и искусства «вмешиваются» в пространство внутренней реальности художественного текста, делая ее блеклой и тусклой, а героев «тихими, невыразительными, бездействующими» [Алтынгужин 2020: 569] по сравнению с их мифологическими и художественными реинкарнациями в скульптурных, сценических и живописных образах. Тем самым, автор оригинала подчеркивает сразу несколько центральных конфликтов произведения, а именно конфликт реальности и творчества, через посредство которого, в 
свою очередь, обнаруживается морально-этический конфликт сразу нескольких персонажей, чьи мифологические и художественные образы более возвышенны и благородны по сравнению с реальными. Таким образом, особое структурносемиотическое усложнение художественного текста напрямую влияет на его смысловое содержание. Более того, следует отметить, что особое значение семиотических пространств искусства и мифа акцентируется автором оригинала в названии романа, в котором присутствуют лексемы marble (мрамор/мраморный) и Faun (Фавн), означающих один из основных материалов создания скульптуры и мифологическое существо, соответственно.

Как было отмечено выше, семиотическое пространство танца во многих эпизодах пересекается как с семиотическими пространствами других видов искусств, так и с мифологическим семиотическим пространством, в связи с чем представляется возможным сформировать лингвосемиотические ряды музыки, пластического и декоративного видов искусства, а также мифа, связанного с образом Фавна, на основе тех языковых средств, которые были помещены автором оригинала в один контекст с лексемами, описывающими танцевальные движения. Так, например, к лингвосемиотическому ряду музыки можно отнести такие лексические единицы, как music (музыка), musicians (музыканты), instrument (музыкальный инструмент), tambourine (бубен), tinkling bells (колокольчики), harper (apфuст), violin player (скрипач), flautist (флейтист) и др. В лингвосемиотический ряд пластического и декоративного искусства, в свою очередь, можно включить следующие лексемы: marble coffin (мраморная усыпальница), stone seats (каменньле сиденья), stone benches (каменные скамьи), sculptured scene (скульптурная сцена), sarcophagus (саркофаг), antique vase (античная ваза), bas-reliefs (барельеф) и др. Наконец, лингвосемиотический ряд мифа, связанного с образом Фавна, содержит языковые средства, такие как: Sylvan (Сильван), Nymph (Нимфа), Faun (Фавн), Pan (Пан), Dryad (Дриада), satyrs (сатиры), creature of the woods (лесное существо), bacchanals (вакханки) и др.

Отметим, что многие из вышеуказанных лексических единиц были опущены в тексте перевода, из-за чего «значительный пласт...информации может оказаться бесследно утерянным для 
реципиента, а смыслообразующие функции» семиотических пространств мифа и искусства «нивелируются, что может привести к искажению понимания смысла художественного текста» [Морозкина, Биктимирова, Исхакова 2018: 541]. Наиболее иллюстративным в этом отношении является отрывок, приведенный ниже:

The harper thrummed with rapid fingers; the violin player flashed his bow back and forth across the strings; the flautist poured his breath in quick puffs of jollity, while Donatello shook the tambourine above his head...it seemed the realization of one of those bas-reliefs where a dance of nymphs, satyrs, or bacchanals is twined around the circle of an antique vase; or it was like the sculptured scene on the front and sides of a sarcophagus...

В данном отрывке описывается сцена танца двух героев под музыку уличных музыкантов, которая сравнивается со сценами на старинных, античных барельефах и вазах, изображающих танцы мифологических персонажей. Как видим, здесь происходит сопряжение и взаимоналожение сразу нескольких семиотических пространств за счет включения в единый контекст языковых средств, отмеченных нами ранее и формирующих различные семиотические пространства. Приведенный в качестве примера эпизод, безусловно, является одним из ключевых в анализируемом художественном тексте, однако переводчик оставляет его полностью непереведенным, что ведет за собой негативные последствия для интерпретации реципиентом текста перевода. Опущение целого отрывка текста оригинала, содержащего в себе важные лексические единицы, выполняющие структурно-смысловую и семиотическую функции, так или иначе нарушает целостность восприятия текста, поскольку опущенные лексемы во многом определяют специфику текста и отсутствие этих лексем не позволяет «разгадать ключевой алгоритм построения текста» [Морозкина, Камалов 2013: 89], а также препятствует выявлению имплицитных смыслов, заложенных автором оригинала.

В целом, анализ текста романа «Мраморный Фавн» позволил прийти к выводу, что данный текст отличается сложно организованной структурой, объединяющей в себе мифологическое семиотическое пространство, а также семиотические пространства отдельных видов искусств. В ходе 
анализа было выявлено, что означенные семиотические пространства были введены автором, с одной стороны, для формирования структурной связи различных эпизодов текста, с другой - для передачи имплицитных смыслов, связанных с внутренними конфликтами произведения. В частности, важнейшую роль в структурно-семиотической и смысловой организации проанализированного текста играет семиотическое пространство танца, одновременно сопряженное с семиотическими пространствами других видов искусств. Анализ текста перевода, в свою очередь, показал, что многие лексические средства, актуализирующее то или иное семиотическое пространство, оказались неучтенными, в результате чего большая часть смысловых оттенков осталась непереданной. Для того чтобы избежать подобных переводческих недостатков, необходимо внимательно проанализировать текст оригинала, выявить языковые средства, которые отвечают за формирование структурносемиотических связей внутри текста и объединить данные средства в языковые групाы, что обеспечит целостное видение смыслового наполнения текста и определить скрытовыраженные в тексте смыслы.

\section{ЛИТЕРАТУРА}

1. Алтынгужин Т. Р. Функщии семиотического пространства различных видов искусств в орипинале и переводе романа Н. Готорна «Мраморный фавн» // Вестник БашГ У. 2020. Т. 25. №3. С. 567-571

2. Готорн Н. Мраморный Фавн. Спб.: типография Глазунова, 1860. 294 с.

3. Лотман Ю. М. Избранные статьи: в 3-х тт. Т. 1: Статыи по семиотике и топологии культуры. Таллинн: Александра, 1992.С. 13-24.

4. Лотман Ю. М. Статы по семиотике культуры и искусства. СПб.: Академическийпроект, 2002.544 с.

5. Морозкина Е. А., Биктимирова М. М. «Текст в тексте» в пространственной структуре оригинала и перевода романа Н. Готорна «Мраморный фавн» // Вестник БашГ У. 2018. Т. 23. №1. С. 238-243.

6. Морозкина Е. А., Биктимирова М. М, Исхакова Э. В. Библейская метафора в художественном тексте// Вестник БашГ У. 2018. Т. 23. №2. С. $538-542$.

7. Морозкина Е. А., Камалов Р. И. Художественная реализация модели «Внугреннее-внешнее» в композиции романа Н. Готорна «Дом о семи фронтонах» // Вестник БашГ У. 2013. Т. 18. №1. С. 89-93. 
8. Морозкина Е. А., Камалов Р. И., Кожевников М. В. Моделирование пространства и художественных образов в творчестве Н. Готорна // Вестник БашГУ. 2014. Т. 19. №3. С. 1004-1006.

9. Морозкина Е. А., Морозкин Ю. Н., Сафина 3. М. Пространственные предлоги в свете теории фракталов // Вестник Чувашского ун-та. 2017. №2. C. 269-276.

10. Hawthorne N. The Marble Faun. URL: http:/www.eldritchpress.org/nh/mf.html (дата обращения: 28.08.2020).

(С) Морозкина Е.А., Алтынгужин Т.Р., 2021 г. 